\title{
Isolation, Characterization and Antimicrobial Activities of Actinomycetes Isolated from a Tunisian Saline Wetland
}

Ines Trabelsi' ${ }^{1}$, Daniel Oves², Beatriz Gutierrez Magan ${ }^{3}$, Angel Manteca $^{3}$, Olga Genilloud ${ }^{2}$ and Mohamed Nour ${ }^{1,4 *}$

${ }^{1}$ Research Laboratory "Bioressources: Biologie Intégrative and Valorisation" BIOLIVAL, Higher Institute of Biotechnology of Monastir, University of Monastir, Tunisia ${ }^{2}$ Fundación MEDINA, Parque Tecnológico Ciencias de la Salud, Granada, Spain

${ }^{3}$ Área de Microbiología, Departamento de Biología Funcional e IUOPA, Facultad de Medicina, Universidad de Oviedo, Spain

${ }^{4}$ Taif University, College of Science, Laboratory of Applied and Molecular Microbiology, Saudi Arabia

\begin{abstract}
The "Sebkha of Monastir" is a Tunisian permanent wetland that constitutes a virgin environment to search new biotechnologically relevant microorganisms and activities. A total of 71 different strains were isolated, including 54 Streptomyces, 2 Micromonospora, 2 Nocardia, 4 Pseudonocardia and 9 non-streptomyces actinomyetes. Interesting antimicrobial activities were detected in liquid and solid cultures. The antimicrobial profiles depended upon the culture medium and/or the organic extraction. Several bioactive compounds were identified by liquid chromatography (LC) combined with mass spectrometry (MS) and then analyzed by MEDINA's database and the Dictionary of Natural Products Chapman \& Hall. Isoflavones (genistein and deidzein) are the most produced known active compounds. The chemical structures of four putative novel compounds were elucidated. Interestingly, unknown compounds produced by two strains (A8 and A11) actives against Gram negative bacteria were selected for further analysis on a large-scale. 16S rDNA sequencing allowed us to classify some active isolates as members of the Streptomyces and Micromonospora genera. All these findings prove the high antimicrobial activity of the actinomycetes strains isolated from the "Sebkha of Monastir". The potential of this and other relatively unexplored extreme environments constitute a source of new biologically active secondary metabolites.
\end{abstract}

Keywords: Streptomyces; Actinomycetes; Screening; Antibiotic; Wetland

\section{Introduction}

The search for novel antibiotics becomes paramount to counter the development of resistant pathogens, the evolution of new diseases and the toxicity of some of the current compounds [1]. Significant advancement is being made in chemical synthesis and engineered biosynthesis of biomolecules, however nature remains the richest and the most versatile source for new antimicrobial compounds [2].

Among the antibiotic producing microbes, actinomycetes represent a tremendous capacity to produce structurally diverse metabolites with broad range of distinct activities [3]. The members of the genus Streptomyces produces the majority of the naturally occurring metabolites discovered up to date [4]. However, in recent years, the rate of discovering new antibiotics was declining due to the exhaustion of common resources [5]. In fact, the environment can affect microbial metabolism thus antibiotics producing microorganisms have been isolated from unusual habitats [6]. Several research studies are currently oriented towards isolation of interested actinomycetes from un- and under-explored soil habitats [7]. Extremophilic actinomycetes are the most promising source for antimicrobial compounds due to their unique and diverse community structure and various unexplored metabolic pathways [8]. Despite these findings, little is known about the diversity of actinomycetes in saline environments which constitute an uncommon extreme ecosystem [9].

No significant studies have been conducted so far to carry on the presence, the ecological distribution, and the antimicrobial potential of actinomycetes in various ecosystems of Tunisia, especially the saline wetlands. The "Sebkha of Monastir" (1,000 ha; $\left.35^{\circ} 45^{\prime} \mathrm{N} 010^{\circ} 46^{\prime} \mathrm{E}\right)$ is a permanent saline wetland on the central coast of Tunisia, called salt evaporation ponds, salterns or salt pans. It's a saline coastal lagoon with variable salinity and nutrient value. It's connected to the sea by two relatively broad channels. It is a natural salt marsh and a representative example of the rare Western Palearctic wetland type (http://www.ramsar.org).
With the aim of identifying new sources of antibiotics and discovering promising pharmacologically active compounds from actinomycetes, we examined such a rarely explored area rich of biodiversity was examined.

\section{Materials and Methods}

\section{Samples collection}

The "Sebkha of Monastir" was divided in seven experimental zones (Figure 1) according to its physico-chemical characteristics (Table 1). Soil samples were taken from a $10 \mathrm{~cm}$ depth, collected into sterile bottles and stored in ice. Density, salinity and $\mathrm{Ca}^{2+}, \mathrm{Mg}^{2+}, \mathrm{SO}_{4}$ and $\mathrm{KCl}$ content of the sediment samples were measured on the basis of standard methods of Usiglio [10]. A weight of one gram of each soil sample was air-dried, mixed with $0.1 \mathrm{~g}$ of $\mathrm{CaCO}_{3}$ and incubated at $28^{\circ} \mathrm{C}$ for seven days in an atmosphere saturated with moisture [11].

\section{Isolation and identification of actinomycetes}

Actinomycetes were isolated by serial dilution method from sediments [4]. Stock solution was prepared by diluting $1 \mathrm{~g}$ of sediment in $9 \mathrm{ml}$ of sterile saline water and well mixed. Sample was diluted up to $10^{-5}$ and aliquots $(0.1 \mathrm{ml})$ of each dilution were spreadon Glucose-

*Corresponding author: Mohamed Nour, Taif University, College of Science, Laboratory of Applied and Molecular Microbiology, Saudi Arabia, Tel: +966 557115241; Fax: +966 127256500; E-mail: mohamednour2805@yahoo.fr

Received October 05, 2016; Accepted October 20, 2016; Published November 06, 2016

Citation: Trabelsi I, Oves D, Magan BG, Manteca A, Genilloud O, et al. (2016) Isolation, Characterization and Antimicrobial Activities of Actinomycetes Isolated from a Tunisian Saline Wetland. J Microb Biochem Technol 8: 465-473. doi: 10.4172/1948-5948.1000326

Copyright: ( $\odot 2016$ Trabelsi I, et al. This is an open-access article distributed under the terms of the Creative Commons Attribution License, which permits unrestricted use, distribution, and reproduction in any medium, provided the original author and source are credited. 
Citation: Trabelsi I, Oves D, Magan BG, Manteca A, Genilloud O, et al. (2016) Isolation, Characterization and Antimicrobial Activities of Actinomycetes Isolated from a Tunisian Saline Wetland. J Microb Biochem Technol 8: 465-473. doi: 10.4172/1948-5948.1000326

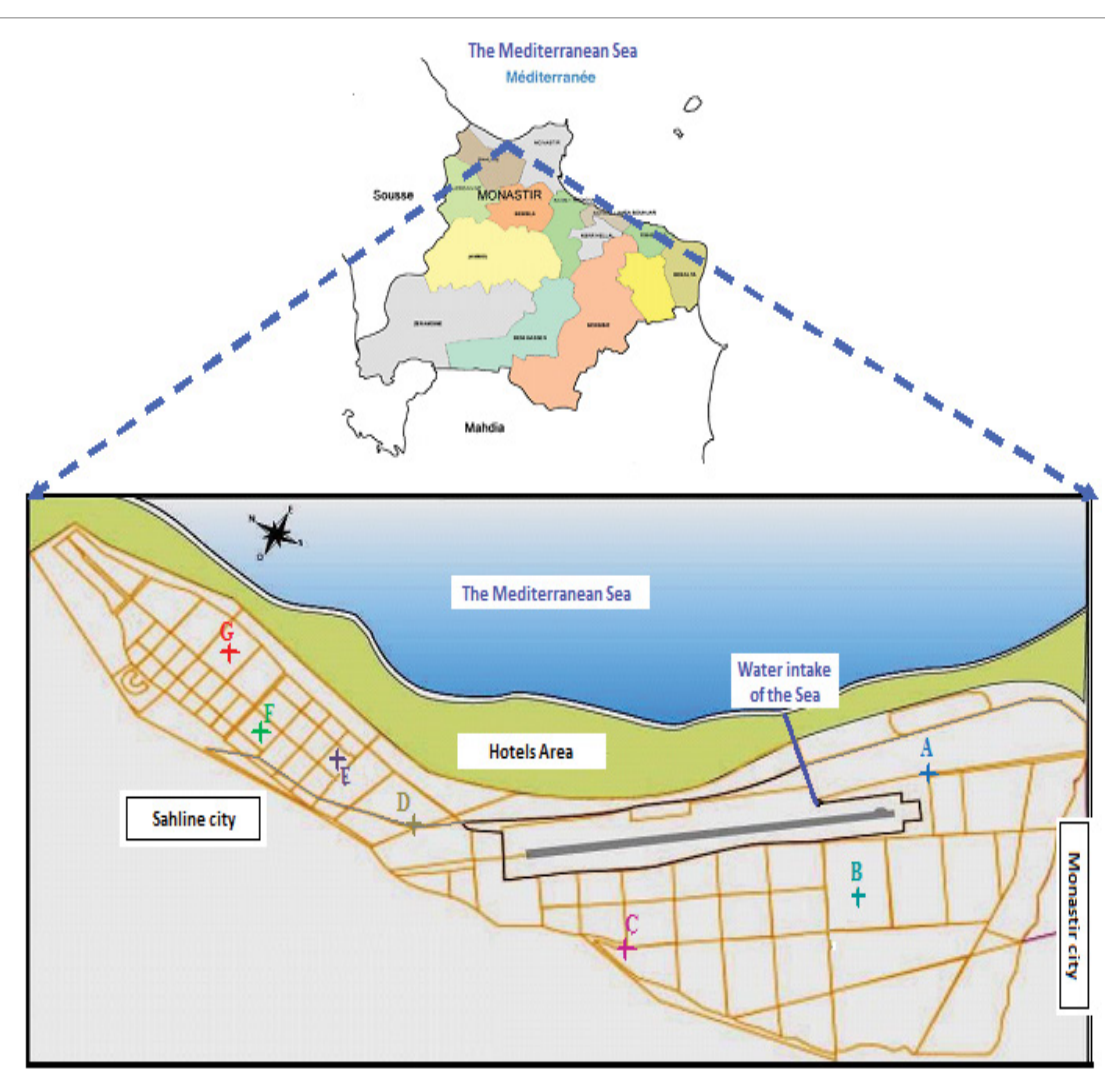

Figure 1: 1 Scheme of the "Sebkha of Monastir" and illustration of the sampling zones (A to G) (Figure adapted from the "General Company of salt pans in Tunisia COTUSAL)"). The surface of the salt ponds: $91.67 \mathrm{Ha}$, Reserve ponds: $15 \mathrm{Ha}$, Bassin for concentrating salt water in salt marshes: $800 \mathrm{Ha}$, Storage area, workshops and other buildings: $6.7 \mathrm{Ha}$.

\begin{tabular}{|c|c|c|c|c|c|c|c|c|c|}
\hline Zones & Description & $\begin{array}{l}\text { Number of } \\
\text { Actinomycete } \\
\text { isolates }\end{array}$ & Bacteria & Density $\left(\mathbf{g} / \mathrm{cm}^{3}\right)$ & $\mathrm{Ca}(\mathrm{g} / \mathrm{l})$ & $M g(g / l)$ & SO4 (g/l) & $\mathrm{KCl}(\mathrm{g} / \mathrm{l})$ & $\mathrm{NaCl}(g / l)$ \\
\hline A & $\begin{array}{l}\text { The entrance of the "Sebkha": near } \\
\text { the water intake of the sea }\end{array}$ & 11 & A1-A11 & $1024 \pm 1.5$ & $0.4 \pm 0.06$ & $1.4 \pm 0.05$ & $2.8 \pm 0.1$ & $0.7 \pm 0.04$ & $28.4 \pm 0.09$ \\
\hline B & $\begin{array}{l}\text { A salt ponds } \\
\text { (191 hectare) }\end{array}$ & 17 & $\begin{array}{l}\text { B1-B3 } \\
\text { B5-B18 }\end{array}$ & $1066 \pm 0.9$ & $1.1 \pm 0.07$ & $3.6 \pm 0.08$ & $7.2 \pm 0.08$ & $1.9 \pm 0.05$ & $74.1 \pm 0.1$ \\
\hline C & The east exit of the salt pan & 6 & C1-C6 & $1099 \pm 0.6$ & $1.6 \pm 0.05$ & $5.4 \pm 0.05$ & $10.5 \pm 0.04$ & $2.8 \pm 0.05$ & $110.3 \pm 0.07$ \\
\hline D & $\begin{array}{l}\text { The intersection of two successive } \\
\text { salt ponds }\end{array}$ & 7 & D1-D7 & $1108 \pm 0.8$ & $1.7 \pm 0.08$ & $5.9 \pm 0.03$ & $11.4 \pm 0.06$ & $3.1 \pm 0.02$ & $119.9 \pm 0.05$ \\
\hline $\mathrm{E}$ & A salt ponds (46 hectare ) & 16 & E1-E16 & $1124 \pm 1$ & $1.5 \pm 0.05$ & $7 \pm 0.09$ & $12.5 \pm 0.08$ & $3.7 \pm 0.02$ & $142.3 \pm 0.1$ \\
\hline $\mathrm{F}$ & A salt ponds (22 hectare) & 5 & F1-F5 & $1170 \pm 0.4$ & $1.1 \pm 0.02$ & $9.9 \pm 0.06$ & $15.1 \pm 0.09$ & $5.2 \pm 0.05$ & $201 \pm 0.05$ \\
\hline G & The saltiest brine (or pickle) & 9 & G1-G9 & $1230 \pm 1.6$ & $1.0 \pm 0.05$ & $26.5 \pm 0.05$ & $28.6 \pm 0.05$ & $12.2 \pm 0.08$ & $218.6 \pm 0.07$ \\
\hline Average & & & & $1117 \pm 0.9$ & $1.2 \pm 0.05$ & $8.5 \pm 0.05$ & $12.6 \pm 0.07$ & $4.2 \pm 0.04$ & $127.8 \pm 0.07$ \\
\hline
\end{tabular}

Table 1: Physico-chemical characteristic of the different sampling zones and number/code of isolated actinomycetes strains. Data correspond to the average and the SD from three independent measures.

Yeast Extract-Agar (GYEA) medium aseptically [12]. The media was supplemented with cycloheximide $(50 \mu \mathrm{g} / \mathrm{ml})$ to prevent fungal contamination [7]. For each sample three plates were used and incubated at $28^{\circ} \mathrm{C}$ for $7-14$ days. The plates were observed periodically for the growth of actinomycetes [4]. Isolated colonies were picked and restreaked several times in order to obtain pure cultures. The obtained isolates were stored at $-80^{\circ} \mathrm{C}$ in agar blocks submerged in $20 \%$ of glycerol or liquid cultures supplemented with $10 \%$ glycerol.

A number of 71 actinomycetes were isolated and examined for colony and microbiological criteria, with special emphasis on pigmentation, diameter, colonial elevation, consistency and opacity. The morphological features of spores, sporangia and aerial and substrate mycelium were observed and recorded. Actinomycetes were recognized on the basis of these morphological criteria [13].

\section{Effect of culture media on antimicrobial activity}

Antimicrobial activity was analysed in both liquid and solid culture.

In fact, several liquid culture media were applied in order to test antimicrobial activities of the isolated actinomycetes (Table 2). The designed media and their composition are as follows (per one litre of distilled water): GCM (glucose $5 \mathrm{~g}$, peptone of soya $20 \mathrm{~g}$, MOPS 10.5 g, yeast extract $1.5 \mathrm{~g}, \mathrm{CaCl}_{2} 0.34 \mathrm{mM}, \mathrm{pH}$ 6.8) (Braña AF, personal communication); GHSA $\left(\mathrm{MgSO}_{4}{ }^{\star} 7 \mathrm{H}_{2} \mathrm{O} 0.6 \mathrm{~g}\right.$, glucose $10 \mathrm{~g}$, soya flour $10 \mathrm{~g}$, yeast extract $0.5 \mathrm{~g}$, MOPS (morpholino-propane-sulfonic acid) 
Citation: Trabelsi I, Oves D, Magan BG, Manteca A, Genilloud O, et al. (2016) Isolation, Characterization and Antimicrobial Activities of Actinomycetes Isolated from a Tunisian Saline Wetland. J Microb Biochem Technol 8: 465-473. doi: 10.4172/1948-5948.1000326

$21 \mathrm{~g}, \mathrm{CaCl}_{2} 20 \mathrm{mM}$, trace element solution $2 \mathrm{ml}, \mathrm{pH}$ 6.8) (Braña AF, personal communication, trace element solution as described by Kieser et al. [14]); FPY-12: 20 g Fructose, 10 g Glucose, $10 \mathrm{~g}$ Maltose, $5 \mathrm{~g}$ Bacto Peptone, $5 \mathrm{~g}$ Amicase, $1 \mathrm{ml}$ Trace Elements (For $100 \mathrm{ml}: 100$ mg Cl $2 \mathrm{Mn} .4 \mathrm{H}_{2} \mathrm{O}, 100 \mathrm{mg} \mathrm{Cl} 2 \mathrm{Zn}, 100 \mathrm{mg} \mathrm{Cl} \mathrm{Fe}_{2} 4 \mathrm{H}_{2} \mathrm{O}, 50 \mathrm{mg} \mathrm{NaI}, \mathrm{pH}$ 7.0); DEF-15: $40 \mathrm{~g}$ Sucrose, $2 \mathrm{~g} \mathrm{ClNH}_{4}, 2 \mathrm{~g} \mathrm{SO}_{4} \mathrm{Na}_{2}, 1 \mathrm{~g} \mathrm{~K}_{2} \mathrm{HPO}_{4}, 1 \mathrm{~g}$ $\mathrm{Cl}_{2} \mathrm{Mg} \cdot 6 \mathrm{H}_{2} \mathrm{O}, 1 \mathrm{~g} \mathrm{ClNa}, 1 \mathrm{ml}$ Trace Elements, $\mathrm{pH} 7.0$ and add $2 \mathrm{~g} \mathrm{Co}_{3} \mathrm{Ca}$ after autoclave; DEF-15S: the same composition of DEF-15 media except the quantity of sucrose $(5 \mathrm{~g})$ and the addition of $20 \mathrm{~g}$ of the Soluble starch from potato, used for the slow growing actinomycetes; KHC: 20 g Dextrin from corn type I, 10 g Beta Cyclo Dextrin, 20 g Tomato Paste, 10 g Primary yeast, $5 \mathrm{mg} \mathrm{CaCl} .6 \mathrm{H}_{2} \mathrm{O}, \mathrm{pH}$ 7.2; FR23: $5 \mathrm{~g}$ Glucose, $30 \mathrm{~g}$ Soluble Starch from Potato, $20 \mathrm{~g}$ Cane Molasses, 20 g Pharmamedia (Cottonseed flour), pH 7.0; GPA: 45 g Glucose, $10 \mathrm{~g}$ Peptonized milk, $1.5 \mathrm{~g}$ Ardamina, pH 7; R358: $10 \mathrm{~g}$ Starch From Potato, $4 \mathrm{~g}$ Bacto Yeast Extract, $2 \mathrm{~g}$ Bacto Peptone, $5 \mathrm{ml} \mathrm{FeSO}_{4} .7,5 \mathrm{ml} \mathrm{KBr}, \mathrm{pH}$ 7.0; APM-9: $50 \mathrm{~g}$ Glucose, $12 \mathrm{~g}$ Soluble Starch from Potato, $30 \mathrm{~g}$ Soy Flour, $2 \mathrm{mg} \mathrm{COCl} .6 \mathrm{H}_{2} \mathrm{O}, 7 \mathrm{~g} \mathrm{CO}_{3} \mathrm{Ca}$ (Add after adjusting $\mathrm{pH}$ ), $\mathrm{pH} 7.0$, used for the slow growing actinomycetes strains.

Solid culture media were used to test the antimicrobial activity of some isolated actinomycetes: R5A modified: $\mathrm{K}_{2} \mathrm{SO}_{4} 0.25 \mathrm{~g} / \mathrm{L}$ $\mathrm{MgCl}_{2}{ }^{*} 6 \mathrm{H}_{2} \mathrm{O} 10.12 \mathrm{~g} / \mathrm{L}$, glucose $10 \mathrm{~g} / \mathrm{L}$, DifcoCasamino acids $0.1 \mathrm{~g} / \mathrm{L}$, oligo elements $200 \mu \mathrm{l}(10 \mathrm{x})$, yeast extract $5 \mathrm{~g} / \mathrm{L}$ and MOPS $21 \mathrm{~g} / \mathrm{L}, 20$ g agar, adjust PH 6.8 [15]. SFM: mannitol $20 \mathrm{~g} / \mathrm{L}$, soya flour $20 \mathrm{~g} / \mathrm{L}, 20$ g agar [14]. GCM and GHSA (detailed above). Isolated actinomycetes were grown on Petri dishes ( $9 \mathrm{~cm}$ diameter, $25 \mathrm{ml}$ of medium per plate) inoculated with $10^{7}$ spores and incubated for 7 days at $30^{\circ} \mathrm{C}$

\section{Fermentation and organic extraction}

Actinomycetes cultivated in liquid medias were pre-cultured in ATCC-2 liquid media (g/L: 20 Soluble starch from potato, 10 Dextrose, 5 NZ Amine type E, 3 Difco Beef extract, 5 Bacto Peptone, 5 Bacto Yeast extract, $\mathrm{pH}$ adjusted to 7 with $\mathrm{NaOH}$ prior to addition of $1 \mathrm{~g} \mathrm{CaCO}_{3}$ ). The isolates were micro-fermented in 96-deep plates well following the Duetz system assay [16]. Different media were inoculated with spores/ mycelia, and incubated at $28^{\circ} \mathrm{C}$, during 7 days for Streptomyces and Nocardia, and during 15 days for Micromonospora, Pseudonocardia and the non-Streptomyces strains. Cellular extracts were generated adding $800 \mu \mathrm{l}$ of acetone and $80 \mu \mathrm{l}$ of Dimethyl-sulfoxyde (DMSO), in each well. The organic extract was concentrated to dryness and used for the analysis of the antimicrobial activities.

From solid culture, the organic extraction was performed using ethyl acetate with and without $1 \%$ formic acid. Solid culture media was minced, resuspended in the organic solvent, shaken at $489 \mathrm{rpm}$ for $1 \mathrm{~h}$ at room temperature and the supernatant was vacuum-dried and stored at $-80^{\circ} \mathrm{C}$

\section{Antimicrobial activity}

The antimicrobial activity was analysed using the Kirby Bauer diffusion method [17].

Antimicrobial activity of the isolated actinomycetes in liquid media was assessed, after organic extraction, using Tecan Aquarius Robot Spotlight. Clinically relevant pathogenic microorganisms were targeted: Candida albicans, Methicillin-resistant Staphylococcus aureus (MRSA), Staphylococcus aureus ATCC6538P, Acinetobacter baumanniiATCC5973, Pseudomonas aeruginosa ATCC5919 and Escherichia coli ESS (Gram negative bacteria, are originally from A.L. Demain, Department of Biology, Massachusetts Institute of Technology, Cambridge). Bacteria were grown on Luria-Bertani (LB) and Brain Heart Infusion (BHI) for Gram negative and Gram positive bacteria culture, respectively. Candida albicans was grown on Sabouraud agar medium. Bacteria were incubated at $37^{\circ} \mathrm{C}$ for $24 \mathrm{~h}$ and Candida albicans at $28^{\circ} \mathrm{C}$ for $48 \mathrm{~h}$.

In solid culture, the antimicrobial activities were analysed against three marker microorganisms: Staphylococcus aureus ATCC 6538P, Escherichia coli ESS and Saccharomyces cerevisiae. Antimicrobial activities were assayed by the agar diffusion method (well technique) before extraction, using agar cylinders of $0.5 \mathrm{~cm}$ diameter; and after extraction using $10 \mu \mathrm{l}$ of the cellular extracts resuspended in $100 \mu \mathrm{l}$ of $50 \%$ DMSO solution, on sterile filter paper disks of $5 \mathrm{~mm}$. Bacteria were incubated at $37^{\circ} \mathrm{C}$, and the yeast at $30^{\circ} \mathrm{C}$.

\section{Partial characterization of the antimicrobials compounds}

Samples injected in the LC-MS were the more active extracts

\begin{tabular}{|c|c|c|c|c|c|c|c|c|c|}
\hline Medina ID & $\begin{array}{l}\text { External } \\
\text { ID }\end{array}$ & $\begin{array}{l}\text { Fermen-tation } \\
\text { Medium }\end{array}$ & MRSA & $\begin{array}{c}\text { S. aureus } \\
\text { ATCC } 6538 P\end{array}$ & C. albicans & $\begin{array}{c}\text { A. baumannii } \\
5973\end{array}$ & $\begin{array}{c}\text { P. aeruginosa } \\
5919\end{array}$ & E. coli ESS & Identification \\
\hline CA-284367 & E1 & DEF-15S & $20 \mathrm{~mm}$ & $22 \mathrm{~mm}$ & NO & NO & NO & Weak halo & Non-streptomyces \\
\hline CA-284375 & E9 & FPY-12 & $15 \mathrm{~mm}$ & $15 \mathrm{~mm}$ & Small & NO & NO & $15 \mathrm{~mm}$ & Non-streptomyces \\
\hline CA-284364 & D5 & FPY-12 & $18 \mathrm{~mm}$ & NO & NO & NO & NO & NO & Pseudo-nocardiaceae \\
\hline CA-284330 & A7 & FPY-12 & $8 \mathrm{~mm}$ & $14 \mathrm{~mm}$ & NO & NO & NO & $15 \mathrm{~mm}$ & Streptomyces \\
\hline CA-284350 & B15 & GCM & Small & $13 \mathrm{~mm}$ & Small & NO & weak halo & weak halo & Streptomyces \\
\hline CA-284331 & A8 & GHSA & $13 \mathrm{~mm}$ & $8 \mathrm{~mm}$ & NO & $11 \mathrm{~mm}$ & Small & $14 \mathrm{~mm}$ & Streptomyces \\
\hline CA-284334 & $\mathrm{A} 11$ & GHSA & $15 \mathrm{~mm}$ & $8 \mathrm{~mm}$ & NO & $12 \mathrm{~mm}$ & NO & NO & Streptomyces \\
\hline CA-284340 & B5 & GHSA & NO & NO & $16 \mathrm{~mm}$ & NO & $\mathrm{NO}$ & NO & Streptomyces \\
\hline CA-284345 & B10 & GHSA & NO & NO & $16 \mathrm{~mm}$ & NO & NO & NO & Streptomyces \\
\hline CA-284369 & E3 & GHSA & NO & NO & NO & $7 \mathrm{~mm}$ & $\mathrm{NO}$ & NO & Streptomyces \\
\hline CA-284365 & D6 & FR23 & $12 \mathrm{~mm}$ & $10 \mathrm{~mm}$ & $\mathrm{NO}$ & $\mathrm{NO}$ & $\mathrm{NO}$ & $15 \mathrm{~mm}$ & Streptomyces \\
\hline CA-284329 & A6 & GPA & $18 \mathrm{~mm}$ & $15 \mathrm{~mm}$ & NO & NO & NO & $18 \mathrm{~mm}$ & Streptomyces \\
\hline CA-284333 & A10 & GPA & $17 \mathrm{~mm}$ & $14 \mathrm{~mm}$ & NO & NO & NO & $17 \mathrm{~mm}$ & Streptomyces \\
\hline CA-284370 & E4 & GPA & $17 \mathrm{~mm}$ & $14 \mathrm{~mm}$ & NO & NO & NO & $15 \mathrm{~mm}$ & Streptomyces \\
\hline CA-284376 & E10 & GPA & $18 \mathrm{~mm}$ & $15 \mathrm{~mm}$ & NO & NO & NO & $20 \mathrm{~mm}$ & Streptomyces \\
\hline CA-284380 & E14 & GPA & $10 \mathrm{~mm}$ & $12 \mathrm{~mm}$ & NO & NO & NO & $14 \mathrm{~mm}$ & Streptomyces \\
\hline CA-284381 & E15 & R358 & $20 \mathrm{~mm}$ & $18 \mathrm{~mm}$ & NO & NO & NO & NO & Streptomyces \\
\hline CA-284337 & B2 & DEF-15 & $18 \mathrm{~mm}$ & $13 \mathrm{~mm}$ & $\mathrm{NO}$ & $6 \mathrm{~mm}$ & $\mathrm{NO}$ & $27 \mathrm{~mm}$ & Streptomyces \\
\hline
\end{tabular}

Table 2: Antimicrobial activities of organic extracts from liquid culture. Only strains and culture media with notable positive antimicrobial activities are shown. 
Citation: Trabelsi I, Oves D, Magan BG, Manteca A, Genilloud O, et al. (2016) Isolation, Characterization and Antimicrobial Activities of Actinomycetes Isolated from a Tunisian Saline Wetland. J Microb Biochem Technol 8: 465-473. doi: 10.4172/1948-5948.1000326

obtained from the Duetz fermentation, mixed with 20\% DMSO. The column used for the chromatographic separation was a Zorbax SBC8 $(2.1 \times 30 \mathrm{~mm}$, particle size: $3.5 \mathrm{~mm})$. Electrospray ionization (ESI) was adjusted to positive mode. The results obtained from each selected component were compared with the MEDINA's database to identify known compounds.

Cellular extracts showing the greatest antimicrobial activity in solid culture were dereplicated by LC-MS using an Agilent 1200 HPLC coupled with a Rapid Resolution Mass Spectrometer. The column used was charged with $1 \mu \mathrm{l}$ of the vacuum-dried sample resuspended in $100 \mu \mathrm{l} 50 \%$ DMSO. Mobile phase A contained $10 \%$ of acetonitrile, $90 \%$ of water and $1.3 \mathrm{mM}$ oftrifluoroacetic acid/ammonium formate and $\mathrm{B}$ contained $90 \%$ of acetonitrile, $10 \%$ of water and $1.3 \mathrm{mM}$ of trifluoroacetic acid/ammonium formate). Gradient $10 \%$ B to $100 \%$ $\mathrm{B}$ in $6 \mathrm{~min}$, hold $2 \mathrm{~min}$, initialize $2 \mathrm{~min}$. The flow rate was $0.3 \mathrm{ml} /$ min and electrospray ionization (ESI) was adjusted to positive mode. Retention time and the mass of each component were compared to the high-resolution database at the MEDINA Foundation and the "Chapman \& Hall Dictionary of Natural Products" [18]. The compound was considered identified if a match was found between the exact mass, molecular formula and producing organism. Molecules were considered potential new compounds if they could not be identified using the Chapman \& Hall database.

\section{Analysis of the antimicrobial activity in bigger scale}

Anti-infective assays on A. baumannii ATCC 5973, P. aeruginosa ATCC 5919, E. coli (envA/tolC) ATCC 5746 from MEDINA's Culture Collection, E. coli wild-type strain ATCC 2884 and E. coli ESS, were using as follows. Inoculum suspensions were streaked onto LB agar plates and incubated at $37^{\circ} \mathrm{C}$ overnight. Single colonies were inoculated into $10 \mathrm{ml} \mathrm{LB}$ broth medium in $250 \mathrm{ml}$ Erlenmeyer flasks. The flasks were incubated overnight at $37^{\circ} \mathrm{C}$ and were suspended until the absorbance at OD $612 \mathrm{~nm}$ was adjusted to 0.35 in LB media and then diluted to $1: 10000$ in order to obtain assay inoculums of approximately 5-6 $\times 10^{5}$ $\mathrm{CFU} / \mathrm{ml}$. For the screening assay $90 \mu \mathrm{l}$ of the diluted inoculums were mixed with $10 \mu \mathrm{l}$ of extracts as well as rifampicin and amphotericin $\mathrm{B}$, included as internal controls, against A. Baumannii 5973, ciprofloxacin and amphotericin $B$ against $P$. aeruginosa and novobiocin and amphotericin B against E. coli.

Pipetting and mixing were performed in a Tecan AQUARIUS pipetting station (Tecan, Durham, USA) and the used plates were microtiter 96-plates Costar 3370 (Corning, NY, USA). The absorbance at OD $612 \mathrm{~nm}$ was measured with a Tecan Ultra Evolution spectrophotometer (Tecan, Durham, USA) at $\mathrm{T}_{0}$ (zero time) then plates were immediately and statically incubated at $37^{\circ} \mathrm{C}$ for $18 \mathrm{~h}$.

After incubation, the test plates were shaken using the DPC Micromix-5 and once more the absorbance at OD $612 \mathrm{~nm}$ was measured at $\mathrm{T}_{\mathrm{f}}$ (final time). Growth inhibition percentage was calculated using the following normalization equation:

$\%$ Inhibition $=100 \times\left\{\frac{\left[\left(\mathrm{T}_{\mathrm{f} \text { Sample }}-\mathrm{T}_{0 \text { Sample }}\right)-\left(\mathrm{T}_{\mathrm{f} \text { Blank }}-\mathrm{T}_{0 \text { Blank }}\right)\right]}{\left[\left(\mathrm{T}_{\mathrm{f} \text { Growth }}-\mathrm{T}_{0 \text { Growth }}\right)-\left(\mathrm{T}_{\mathrm{f} \text { Blank }}-\mathrm{T}_{0 \text { Blank }}\right)\right]}\right\}$ where,

$\mathrm{T}_{0}$ : Sample is the absorbance of the isolates growth in the presence of sample measured at zero time (before incubation)

$\mathrm{T}_{\mathrm{f}}$ : Sample is the absorbance of the isolates growth in the presence of sample measured at final time (after incubation)
$\mathrm{T}_{0}$ : Growth is the absorbance of the isolates growth in the absence of sample measured at zero time (before incubation)

$\mathrm{T}_{\mathrm{f}}$ Growth is the absorbance of the isolates growth in the absence of sample measured at final time (after incubation)

$\mathrm{T}_{0}$ : Blank is the absorbance of the broth medium (blank) measured at zero time (before incubation)

$\mathrm{T}_{\mathrm{f}}$ Blank is the absorbance of the broth medium (blank) measured at final time (after incubation)

An extract is considered to have activity when its percentage of inhibition is more than $70 \%$.

\section{Statistical Analysis}

Statistical analysis was performed using the Statview 4.57 software (Abacus Concepts Inc., Berkeley, CA, USA). Data were subjected to three-way analysis of variance (ANOVA) in order to evaluate the effect of actinomycetes strains, culture media and marker microorganisms on antimicrobial activities. Data correspond to the average and the standard deviation (SD) from three independent measures and values were considered significant when $\mathrm{P} \leq 0.05$.

\section{Phylogenetic analysis of some active isolates}

Genomic DNA from the most actives actinomycetes in solid culture was obtained as previously described by Kieser et al. [14]. The $16 \mathrm{~S}$ rRNA gene was amplified by PCR using universal primers [7].

A total volume of $50 \mu \mathrm{l}$ reaction mixture, contained $2 \mathrm{mM}$ dNTP mixture, $30 \mathrm{pmol} / \mu \mathrm{l}$ of each primer ( $27 \mathrm{f}$ and $1492 \mathrm{r}$ ), $1.5 \mathrm{mM} \mathrm{MgCl}$, 10x polymerase buffer, $0.2 \mu \mathrm{l}$ of Taq DNA polymerase (Biotools). The PCR program was as follows: an initial denaturation step at $95^{\circ} \mathrm{C}$ for $5 \mathrm{~min}$, followed by 30 amplification cycles of $95^{\circ} \mathrm{C}$ for $1 \mathrm{~min} ; 57^{\circ} \mathrm{C}$ for $1 \mathrm{~min}$ and $72^{\circ} \mathrm{C}$ for $90 \mathrm{~s}$ and a final extension step of $72^{\circ} \mathrm{C}$ for 10 min. Amplification products (1500 bp) were detected by agarose gel electrophoresis and were visualized by ultraviolet (UV) fluorescence after ethidium bromide staining. The PCR products extracted from the bands were purified using the GFXTM PCR DNA and Gel Band Purification Kit (Amersham Biosciences) and then sequenced. The $16 \mathrm{~S}$ rDNA sequences were analysed using the Gapped BLAST database search program facility of the National Center for Biotechnology Information (NCBI) [19] and were deposited in the EMBL Nucleotide Sequence Database (Accessions numbers: KF793799, KF793800, KF793805, KF793806, KF793807). Sequence data were aligned and subjected to preliminary analysis within BioEdit program. Phylogenetic analysis was performed with version 6 of the MEGA software package using the neighbor-joining method. Robustness of the inferred tree was assessed by bootstrapping (1000 pseudo-replicates) [20].

\section{Results}

\section{Physicochemical and microbiological analysis of the "Sebkha of Monastir"}

As indicated above and illustrated in Figure 1, seven different zones of the "Sebkha of Monastir" were sampled. As expected, these zones had high salinities (minimum values of $\mathrm{NaCl}$ concentration is $28 \mathrm{~g} / \mathrm{L}$ ), but there were important differences of salinity and ion concentrations between zones (Table 1). The sample G4, the saltiest brine $(\mathrm{NaCl} 218$ $\mathrm{g} / \mathrm{L})$, presents the highest concentration of magnesium $(26.5 \mathrm{~g} / \mathrm{L})$, sulphate $(28.6 \mathrm{~g} / \mathrm{L})$ and potassium $(12.2 \mathrm{~g} / \mathrm{L})$ (Table 1$)$. While calcium content were the highest in the sample D (Table 1). 
Citation: Trabelsi I, Oves D, Magan BG, Manteca A, Genilloud O, et al. (2016) Isolation, Characterization and Antimicrobial Activities of Actinomycetes Isolated from a Tunisian Saline Wetland. J Microb Biochem Technol 8: 465-473. doi: 10.4172/1948-5948.1000326

A total of 71 actinomycetes strains were isolated from the seven sampling zones. Based on phenotypic characteristics macro and microscopic analysis, 4 different genera were described: Streptomyces (54 isolates), Pseudonocardia (4 isolates), Nocardia (2 isolates) and Micromonospora (2 isolates). Only 9 strains, named non-Streptomyces, could not be classified on the basis of the phenotypic characters.

As expected, higher diversity of actinomycetes was found in the low salt concentration zones (A, B and C) while the zones with highest salt concentration were those with lower diversity (zones $\mathrm{F}$ and $\mathrm{G}$ ) (Table 1).

\section{Effect of culture media on antimicrobial activity}

The antimicrobial activities detected in the different used media are quite different. GHSA and GPA media seems to be the most adequate to the growth and antimicrobial production of actinomycetes strains in liquid culture. While GCM and SFM media were very valuables for the detection of antimicrobial activity in solid culture. The culture media with notable positive activity were chosen for further analysis.

\section{Pre-analysis of the antimicrobial activity}

Forty eight strains out of 71 isolates produced, in liquid culture, bioactive compounds against the microorganisms used for bioassay (Table 2): 23 strains were active against MRSA, 22 against $S$. aureus ATCC 6538P, 4 strains inhibited the growth of A. baumannii 5973, 2 strains inhibited $P$. aeruginosa 5919, 36 strains against $E$. coli and 9 strains had antifungal activity against Candida albicans.

ANOVA analysis reported in Table 2 revealed that antimicrobial activity varied significantly (at $\mathrm{P} \leq 0.01$ ) depending on the producing actinomycetes strains, the culture media and the microorganisms test. A significant interaction (at $\mathrm{P} \leq 0.01$ ) between these factors was also detected.

Eleven strains were randomly selected to be analysed in solid culture. Only one strain has no activity against any of the tested microorganisms. Acidic extraction (ethyl acetate with formic acid) was

generally most efficient at extracting antimicrobials. The antimicrobial activity detected in the agar cultures of some strains, was totally lost (A1, G5 and G6) or almost (A2, A3 and A4), after extraction (Table 3).

The results obtained in liquid and in solid culture were quite different as demonstrated in Table 3.

\section{Purification and partial characterization of bioactive molecules}

As detailed in methods, cellular extracts from liquid culture were subjected to chemical dereplication orderly. Several bioactive molecules were identified on the basis of MEDINA's database (Table 4). Deferoxamine, norcardamine and daidzein are the most detected antibiotics from liquid culture. Many detected compounds do not match with any known bioactive molecules present in MEDINA's database, which contains the most common secondary metabolites. These compounds can be subject of others assays to search for new antibiotics.

The organic extracts from 7 strains, showing the most potent antimicrobial activities in solid culture, were selected (A2, A3, A4, G1, G2, G4 and G7) and subjected to chemical dereplication. Several bioactive molecules were identified as antibiotics (genistein, valinomycin, clifednamide B, antibiotic SS8201D, ikarugamycin, griseoviridin, viridogrisein I and II, pentalenolactone, oxazolomycin, mocimycin, 5,6-dihydromocimycin), antifungals (dihydromaltophilin, maltophilin, capsimycin), antiprotozoals (ikarugamycin epoxide) and some antiviral and antitumor agents (Table 5). The genistein is the most detected active compound. Some interesting compounds did not match with any known compound in the Chapman \& Hall database, which suggest the presence of new bioactive molecules (Figure S1). Some of these identified compounds were detected in more than one strain.

\section{Analysis of potential new antimicrobial compounds from strains A8 and A11}

The organic extracts from strains $\mathrm{A} 8$ and A11 showed an

\begin{tabular}{|c|c|c|c|c|}
\hline \multirow{2}{*}{ Strains } & \multirow{2}{*}{ Medina Codes } & \multicolumn{2}{|c|}{ Activity in solid culture (Best Halo of inhibition in $\mathrm{mm}$ ) } & \multirow{2}{*}{$\begin{array}{l}\text { Activity in liquid culture (Best Halo of inhibition } \\
\text { in } \mathrm{mm} \text { ) }\end{array}$} \\
\hline & & Before Extraction & After Extraction & \\
\hline \multirow{3}{*}{ A1 } & \multirow{3}{*}{ CA-284305 } & S. aureus (16 mm) & \multirow{3}{*}{ NO } & S. aureus (32 mm) \\
\hline & & \multirow{2}{*}{ E. coli $(11 \mathrm{~mm})$} & & E. coli (small) \\
\hline & & & & MRSA (small) \\
\hline \multirow{2}{*}{ A2 } & \multirow{2}{*}{ CA-284306 } & S. aureus (15 mm) & \multirow{2}{*}{ S. aureus $(8 \mathrm{~mm})$} & \multirow{2}{*}{ E. coli (small) } \\
\hline & & S.cerviceae $(15 \mathrm{~mm})$ & & \\
\hline A3 & CA-284307 & S. aureus (small) & S. aureus (small) & NO \\
\hline \multirow{2}{*}{ A4 } & \multirow{2}{*}{ CA-284308 } & S. aureus (14 mm) & \multirow{2}{*}{ S. aureus (small) } & \multirow{2}{*}{ E. coli (small) } \\
\hline & & S. cerviceae $(13 \mathrm{~mm})$ & & \\
\hline \multirow{3}{*}{$\mathrm{G} 1$} & \multirow{3}{*}{ CA-284309 } & S. aureus $(28 \mathrm{~mm})$ & S. aureus (32 mm) & \multirow{3}{*}{ E. coli (small) } \\
\hline & & E. coli $(21 \mathrm{~mm})$ & E. coli $(28 \mathrm{~mm})$ & \\
\hline & & & S. cerviceae (small) & \\
\hline \multirow{3}{*}{$\mathrm{G} 2$} & \multirow{3}{*}{ CA-284310 } & S. aureus $(13 \mathrm{~mm})$ & S. aureus $(24 \mathrm{~mm})$ & \multirow{3}{*}{ S. aureus (small) } \\
\hline & & E. coli $(14 \mathrm{~mm})$ & E. coli $(25 \mathrm{~mm})$ & \\
\hline & & S. cerviceae $(17 \mathrm{~mm})$ & S. cerviceae $(8 \mathrm{~mm})$ & \\
\hline G3 & CA-284311 & NO & NO & NO \\
\hline \multirow{2}{*}{ G4 } & \multirow{2}{*}{ CA-284312 } & \multirow{2}{*}{ E. coli $(18 \mathrm{~mm})$} & S. aureus $(8 \mathrm{~mm})$ & \multirow{2}{*}{ E. coli $(10 \mathrm{~mm})$} \\
\hline & & & E. coli $(15 \mathrm{~mm})$ & \\
\hline G5 & CA-284313 & S. aureus (18 mm) & NO & NO \\
\hline G6 & CA-284314 & S. aureus $(18 \mathrm{~mm})$ & NO & E. coli $(10 \mathrm{~mm})$ \\
\hline \multirow{3}{*}{ G7 } & \multirow{3}{*}{ CA-284315 } & S. aureus $(13 \mathrm{~mm})$ & S. aureus (12 mm) & \multirow{3}{*}{ NO } \\
\hline & & S. cerviceae $(25 \mathrm{~mm})$ & E. coli $(11 \mathrm{~mm})$ & \\
\hline & & & S. cerviceae $(21 \mathrm{~mm})$ & \\
\hline
\end{tabular}

Table 3: Comparison between the results of the bioassays obtained in solid culture and those obtained in liquid culture. 
Citation: Trabelsi I, Oves D, Magan BG, Manteca A, Genilloud O, et al. (2016) Isolation, Characterization and Antimicrobial Activities of Actinomycetes Isolated from a Tunisian Saline Wetland. J Microb Biochem Technol 8: 465-473. doi: 10.4172/1948-5948.1000326

\begin{tabular}{|c|c|c|c|c|c|}
\hline \multicolumn{7}{|c|}{ CA\# Number } & $\begin{array}{c}\text { External } \\
\text { ID }\end{array}$ & $\begin{array}{c}\text { Fermentation } \\
\text { Medium }\end{array}$ & $\begin{array}{c}\text { Fermentation } \\
\text { Days }\end{array}$ & Extract ID & LC-MS result \\
\hline CA-284329 & A6 & GPA & 7 & CA-284329-a01-MO001-EC01-a01 & - \\
\hline CA-284330 & A7 & FPY-12 & 7 & CA-284330-a01-MO001-EC01-a01 & - \\
\hline CA-284331 & A8 & GHSA & 7 & CA-284331-a02-MO001-EC01-a01 & - \\
\hline CA-284333 & A10 & GPA & 7 & CA-284333-a01-MO001-EC01-a01 & - \\
\hline CA-284334 & A11 & GHSA & 7 & CA-284334-a02-MO001-EC01-a01 & Deferoxamine, Norcardamine \\
\hline CA-284337 & B2 & DEF-15 & 7 & CA-284337-a01-MO001-EC01-a01 & Deferoxamine, Daidzein \\
\hline CA-284340 & B5 & GHSA & 7 & CA-284340-a01-MO001-EC01-a01 & Daidzein \\
\hline CA-284345 & B10 & GHSA & 7 & CA-284345-a01-MO001-EC01-a01 & Nigericin, Grisorixin \\
\hline CA-284350 & B15 & GCM & 7 & CA-284350-a01-MO001-EC01-a01 & Coproporphyrin IIII, Azalomyine \\
\hline CA-284364 & D5 & FPY-12 & 15 & CA-284364-a01-MO001-EC01-a01 & Deferoxamine, Mer-N 5075A \\
\hline CA-284365 & D6 & FR23 & 7 & CA-284365-a01-MO001-EC01-a01 & - \\
\hline CA-284367 & E1 & DEF-15S & 15 & CA-284367-a01-MO001-EC01-a01 & - \\
\hline CA-284369 & E3 & GHSA & 7 & CA-284369-a01-MO001-EC01-a01 & - \\
\hline CA-284370 & E4 & GPA & 7 & CA-284370-a01-MO001-EC01-a01 & - \\
\hline CA-284375 & E9 & FPY-12 & 15 & CA-284375-a01-MO001-EC01-a01 & - \\
\hline CA-284376 & E10 & GPA & 7 & CA-284376-a01-MO001-EC01-a01 & Sulfomycin I \\
\hline CA-284380 & E14 & GPA & 7 & CA-284380-a01-MO001-EC01-a01 & - \\
\hline CA-284381 & E15 & R358 & 7 & CA-284381-a01-MO001-EC01-a01 & - \\
\hline “-“: No match found & & & & \\
\hline
\end{tabular}

Table 4: Summary of identified compounds in each organic extract from liquid cultures.

outstanding activity against the tested Gram negative bacteria $(A$. baumannii 5973 and P. aeruginosa 5919) (Table 2). The partial characterization of these extracts proved that they can be a putative interesting new biomolecules. Thus, these samples were selected for analysis in bigger scale.

For each regrowth four broths were used ( 2 in EPAs and another 2 in flasks). Those four broths are numbered from 1 to 4 in the Table 6. Obviously, the presence of activity in one of them and its absence in the other three leads to a false positive activity. This is the case of the strain A11 that lost its activity in the third broth against $P$. aeruginosa (Table 6).

Analysis of variance (ANOVA) revealed that antimicrobial activity was effected significantly (at $\mathrm{P} \leq 0.01$ ) by the producing actinomycetes strains and the microorganisms test. A significant interaction (at $\mathrm{P} \leq$ 0.01 ) between the both fixed factors was also detected.

\section{Taxonomic analysis of some active strains}

To further characterize the five strains with the most pronounced antimicrobial activities analyzed by chemical dereplication, a $16 \mathrm{~S}$ rDNA phylogenetic tree was constructed (Figure 2).

$16 \mathrm{~S}$ rDNA sequences of the selected actinomycetes isolated in this work were homologous to sequences from streptomycetes isolated from other saline places, such as Streptomyces spp. (accession number EU551691) isolated from the Atacama Desert (99\% identity with G1) and Streptomyces spp. (accession numbers AY944252) isolated from marine sponges [21] (98.1\% identity with A2). The Micromonospora spp. isolated in this work was highly homologous to Micromonospora spp. (accession EU914133), isolated from a marine sponge (99\% identity with A3).

The neighbour-joining phylogenetic tree show four distinct clusters supported by bootstrap value up to $100 \%$. G1, G2 and A2 presents distinct phyletic lines while A3 and A4 strains were grouped in clusters comprising its closest neighbours based on the evolutionary distance matrix.

\section{Discussion}

Overall, the first isolation and characterization of the actinomycetes and their antimicrobial activities from the "Sebkha of Monastir", a permanent saline wetland, was reported.

Seventy one halotolerant actinomycetes were isolated. Only for different genera were detected. It approve that low taxonomic biodiversity is observed in all most the saline environments around the world (the Great Salt Lake (Utah, USA), the alkaline brines of WadiNatrun (Egypt) and Lake Magadi (Kenya)) [22].

Several factors can affect the antimicrobial potential of the actinomycetes strains.

In fact, analysis of the antimicrobial activities of the isolated strains was quite different in all the used media. These results confirm those obtained by several authors, who showed the influence of the medium composition on the production of antimicrobial molecules. Many searchers demonstrated that the organics components used in some media (glucose, yeast extract, malt extract, meat extract, peptone, etc.) does not favour the production of antibiotics. Nevertheless, the elements that promote the production of antimicrobials compounds by actinomycetes strains can be classified into three main groups [23]:

The organics nutriments which are slowly consumable as starch, asparagine, sucrose, etc. The effects of these ingredients have been studied by many searchers $[24,25]$.

Inorganics salts such as calcium, magnesium, potassium, sodium, ammonium, etc. For example, $\mathrm{CaCO}_{3}$ plays the role of a catalyst by neutralizing the acidification of the media. Furthermore, both sodium and chloride ions affect the osmotic pressure of the solution. Positive action of these elements has been reported inter alia by Kuster and Neumier and Omura et al. [26,27].

Trace elements (such as manganese, zinc, iron, etc.) which are catalyst of chemical reactions and required in bit amounts for the growth, development and physiology of the 
Citation: Trabelsi I, Oves D, Magan BG, Manteca A, Genilloud O, et al. (2016) Isolation, Characterization and Antimicrobial Activities of Actinomycetes Isolated from a Tunisian Saline Wetland. J Microb Biochem Technol 8: 465-473. doi: 10.4172/1948-5948.1000326

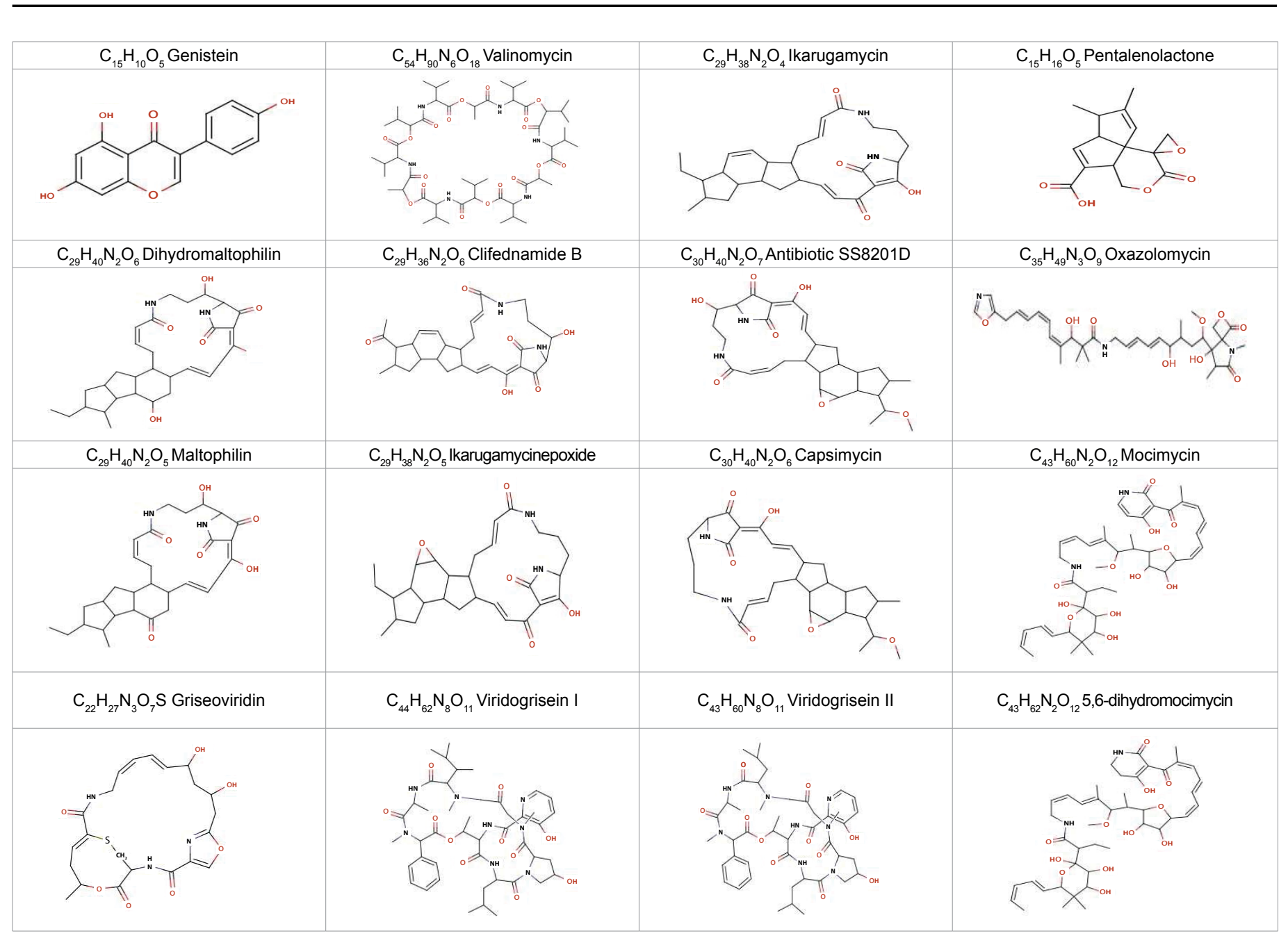

Table 5: Summary of the most interesting compounds extracted from solid cultures and identified in the Chapman and Hall database.

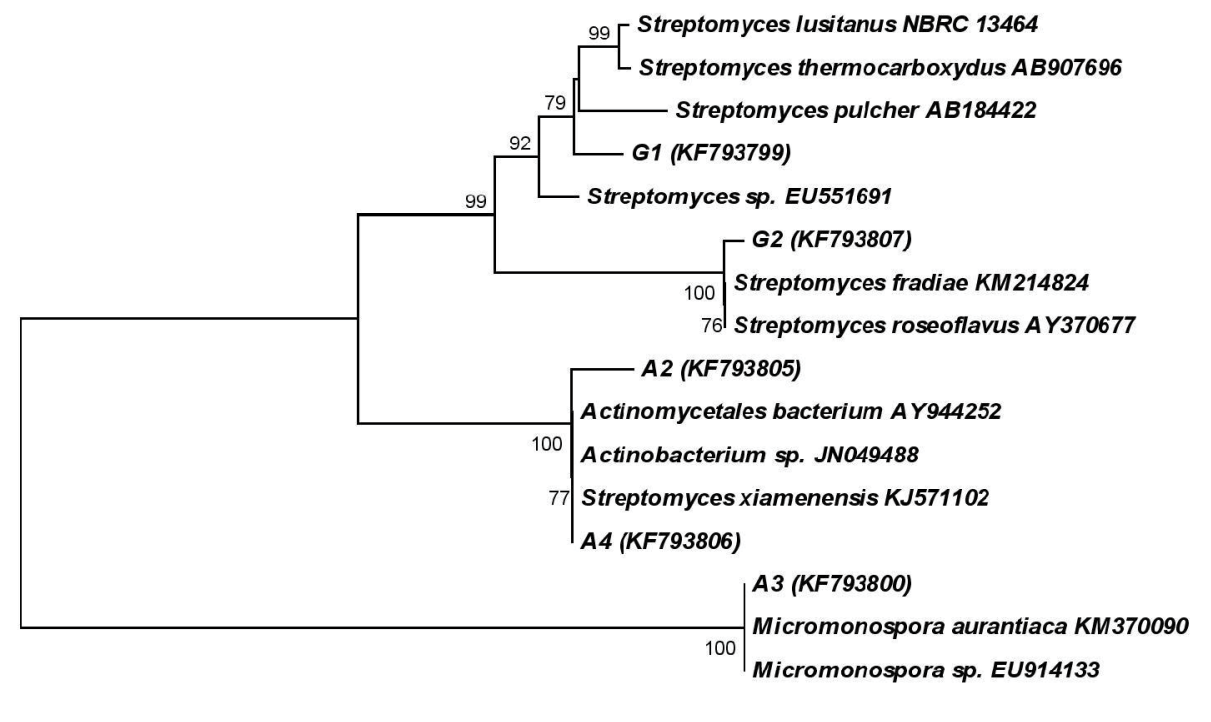

Figure 2: Neighbor-joining phylogenetic tree derived from the 16S rRNA gene sequences of some active actinomyetes isolated in this work, and the most similar sequences of the databases. Percentages at the nodes represent levels of bootstrap support from 1,000 re-sampled datasets; only values of $70 \%$ or above are shown. The scale bar indicates 0.1 substitutions per nucleotide position. Accession numbers are given in parentheses. 
Citation: Trabelsi I, Oves D, Magan BG, Manteca A, Genilloud O, et al. (2016) Isolation, Characterization and Antimicrobial Activities of Actinomycetes Isolated from a Tunisian Saline Wetland. J Microb Biochem Technol 8: 465-473. doi: 10.4172/1948-5948.1000326

\begin{tabular}{|c|c|c|c|c|c|c|}
\hline \multirow{2}{*}{ Isolates } & \multirow{2}{*}{ Compounds } & \multicolumn{5}{|c|}{$\%$ Inhibition } \\
\hline & & E. coli 1 & E. coli 2 & E. coli 3 & A. baumannii & $P$. aeruginosa \\
\hline \multirow{4}{*}{ A8 } & 1 & $-99.7 \pm 0.6$ & $-99.7 \pm 0.6$ & $-102.3 \pm 1.5$ & $-97.3 \pm 1.1$ & $52.3 \pm 4$ \\
\hline & 2 & $-97.3 \pm 3.8$ & $-100 \pm 1$ & $-102 \pm 2$ & $-98.3 \pm 0.6$ & $57 \pm 7$ \\
\hline & 3 & $-98 \pm 2.6$ & $-102 \pm 1.7$ & $-89.3 \pm 0.6$ & $-100 \pm 2.6$ & $6.7 \pm 12$ \\
\hline & 4 & $-100.3 \pm 0.6$ & $-100.7 \pm 0.6$ & $-102 \pm 1$ & $-98 \pm 0$ & $71.7 \pm 6.5$ \\
\hline \multirow{4}{*}{ A11 } & 1 & $-99.7 \pm 0.6$ & $-98.3 \pm 1.1$ & $-99.3 \pm 2$ & $-100.3 \pm 1.5$ & $22 \pm 19.7$ \\
\hline & 2 & $-99.7 \pm 1.5$ & $-99.7 \pm 0.6$ & $-100.7 \pm 1.5$ & $-98 \pm 0$ & $12.3 \pm 5.5$ \\
\hline & 3 & $-95.7 \pm 3.2$ & $-99.7 \pm 4.1$ & $-88.7 \pm 11$ & $-96.7 \pm 3.2$ & $-101 \pm 0$ \\
\hline & 4 & $-99.7 \pm 0.6$ & $-100 \pm 1$ & $-101.3 \pm 1.1$ & $-98.7 \pm 0.6$ & $52 \pm 5.3$ \\
\hline
\end{tabular}

Table 6: Antimicrobial activities (\% inhibition) of the unknown compounds isolated from strains A8 and A11. Data correspond to the average and the SD from three independent measures. Significant antimicrobial values are highlighted in bold.

organism. It explains their beneficial effects in the synthesis of antibiotics [23].

The antimicrobial profile for each strain does not depend only upon the culture medium but also the extraction procedure. Analysis of the antimicrobial activities of some strains, before and after organic extraction, demonstrates that the corresponding extracts from the agar plate cultures were nearly/completely inactive. These results can be explained by the fact that the antimicrobial compounds secreted by these strains are very hydrophilic and cannot be extracted by solvents moderately polar as ethyl acetate. These finding are similar to those obtained by Aouiche et al. [28].

Incidences of activity of the same strains seen in extracts from agar plates were quite different to those obtained in liquid condition. A direct relationship between differentiation processes and secondary metabolite production was reported by Manteca et al. [29]. The mycelium type I (MI) is the Streptomyces vegetative mycelium and the mycelium type II (MII) is the Streptomyces differentiated mycelium producing antibiotics and other secondary metabolites. In solid cultures, two types of MII have been defined based on the absence (in early development) or presence (in late development) of the hydrophobic layers characteristic of aerial hyphae. The unique mycelial phases present in liquid cultures were MI and MII without hydrophobic layers [30]. Growth of actinomycetes in liquid media is very important for the production in large amount of secondary metabolites on an industrial scale.

Various strains show an interesting production of several known bioactive compounds as antibiotics (isoflavones (daidzein and genestein), valinomycin, clifednamide B, antibiotic SS8201D, ikarugamycin, griseoviridin, viridogrisein I and II, oxazolomycin, mocimycin, 5,6-dihydromocimycin, piericidin A, azalomycin, nigericin, grisorixin, Mer-N 5075A, sulfomycin), antifungals (dihydromaltophilin, maltophilin, capsimycin), antiprotozoals (ikarugamycin epoxide), siderophore (Deferoxamine, nocardamine) and some antiviral (pentalenolactone) and antitumor agents (genistein). Interestingly isoflavones (genistein and daidzein) are the most detected bioactive compound in both liquid and solid culture. Isolation and synthesis of isoflavones have become frequent research topics due to their interesting biological activities [31].

Several interesting compounds were detected showing chemical characteristics not listed in MEDINA's and Chapman \& Hall databases. These findings are consistent with those recently published by Guo et al. [7] which approve that such poorly studied soil ecosystems are a potentially rich source of interesting actinomycetes strains able to produce new promising biomolecules. In fact, these bioactive compounds are of great importance and will be subject of further analyses to complete molecular characterization.
Antimicrobials against Gram negative bacteria are, up to date, specially required in clinics [32]. In consequence, efforts were focused in the analysis of these kinds of activities. Thus two strains A8 and A11 were selected for more analysis. The regrowth in bigger scale is important to purify and characterize the putative new bioactive molecules. Liquid culture media were selected to have a biggest quantity of compound. Streptomyces differentiation in liquid cultures has poorly been studied due to the non-sporulation of most Streptomyces strains under these conditions. Despite this limitation, most industrial processes for secondary metabolite production are performed in liquid cultures, being the antibiotics produced by substrate mycelium at the end of the proliferation phase [30].

Taxonomy of the actinomycetes isolated in this work is highly influenced by the saline environment: highly saline environments (The saltiest brine $(218.62 \mathrm{~g} / \mathrm{L} \mathrm{NaCl}))$ were selecting for specific taxa of actinomyetes different to those presented in moderate saline places (salt pond with $28,457 \mathrm{~g} / \mathrm{L} \mathrm{NaCl}$ ) (Figure 2). These results were in agreement with data reported by other authors for the existence of specific specie/ strains of actinomycetes adapted to high saline environments, which are different from those growing in non-saline environments [2].

Phylogenetic analysis of the 16S rRNA gene sequences shows that the strains G1, G2 and A2 formed distinct phyletic lines adjacent to clusters supporting by significant bootstrap values. These strains were preliminarily considered as new genomic species, a result that requires to be confirmed by physiological and biochemical analysis.

All these findings prove the antimicrobial diversity of this relatively unexplored environment and the high potential of this and other unexplored environments, in the screening for new secondary metabolites.

Further studies are required to exploit the Tunisian wetlands potential as sources of new actinomycetes strains and bioactive compounds, including studies aimed to explore the strict halotolerant strains none analysed in this work.

\section{Acknowledgement}

Part of this work was done in A. Manteca's lab (University of Oviedo, Spain). It was funded by the European Research Council (ERC Starting Grant; Strpdifferentiation 280304).

\section{References}

1. Haber M, Ilan M (2014) Diversity and antibacterial activity of bacteria cultured from Mediterranean Axinella spp. sponges. J Appl Microbiol 116: 519-532.

2. Manivasagan P, Venkatesan J, Sivakumar K, Kim SK (2013) Pharmaceutically active secondary metabolites of marine actinobacteria. Microbiol Res 13: 125-200.

3. Demain AL, Sanchez S (2009) Microbial drug discovery: 80 years of progress. J Antibiot 62: 5-16. 
Citation: Trabelsi I, Oves D, Magan BG, Manteca A, Genilloud O, et al. (2016) Isolation, Characterization and Antimicrobial Activities of Actinomycetes Isolated from a Tunisian Saline Wetland. J Microb Biochem Technol 8: 465-473. doi: 10.4172/1948-5948.1000326

4. Gebreyohannes G, Moges F, Sahile S, Raja N, Reetha D (2013) Isolation and characterization of potential antibiotic producing actinomycetes from water and sediments of LakeTana, Ethiopia. Asian Pac J Trop Biomed 3: 426-435.

5. Gao X, Lu Y, Xing Y, Ma Y, Lu J, et al. (2012) A novel anticancer and antifungus phenazine derivative from marine actinomycete BM-17. Microbiol Res 167 616-622.

6. Arasu MV, Duraipandiyan V, Ignacimuthu S (2013) Antibacterial and antifungal activities of polyketide metabolite from marine Streptomyces sp. AP-123 and its cytotoxic effect. Chemosphere 90: 479-487.

7. Guo X, Liu N, Li X, Ding Y, Shang F, et al. (2015) Red soils harbor diverse culturable actinomycetes that are promising sources of novel secondary metabolites. Appl Environ Microbiol 81: 3086-3103

8. Ballav S, Kerkar S, Thomas S, Augustine N (2014) Halophilic and halotoleran actinomycetes from a marine saltern of Goa, India producing anti-bacterial metabolites. J Biosci Bioeng 119: 323-330.

9. Meklat A, Sabaou N, Zitouni A, Mathieu F, Lebrihi A (2011) Isolation, taxonomy, and antagonistic properties of halophilic actinomycetes in Saharan soils of Algeria. Appl Environ Microbiol 77: 6710-6714.

10. Usiglio J (1849) Étude de la composition de l'eau de la Méditerranée et sur l'exploitation des sels qu'elle contient. Annales de chimie et de physique $3^{\circ}$ série 27: 172-191.

11. Cavalla M, Eberlin T (1994) Isolement des streptomycètes du sol. L'opéron 19: 13-17.

12. Boudjella $H$, Bouti $K$, Zitouni A, Mathieu F, Lebrihi A et al. (2007) Isolation and partial characterization of pigment-like antibiotics produced by a new strain of Streptosporangium isolated from an Algerian soil. J Appl Microbiol 103: 228-236.

13. Murray PR, Brenner DJ, Bryant MP, Holt HG, Krieg NR, et al. (1984) Streptomycetes and related genera. In Bergey's Manual of Systematic Bacteriology: Williams \& Wilkins 4: 2451-2508.

14. Kieser T, Bibb MJ, Buttner MJ, Chater KF, Hopwood DA (2000) Practical Streptomyces genetics. John Innes Foundation, Norwich.

15. Fernandez E, Weissbach U, Sanchez-Reillo C, Braña AF, Mendez C, et al. (1998) Identification of two genes from Streptomyces argillaceus encoding glycosyl transferases involved in transfer of a disaccharide during biosynthesis of the antitumor drug mithramycin. J Bacteriol 180: 4929-4937.

16. Graça AP, Bondoso J, Gaspar H, Xavier JR, Monteiro MC, et al. (2013) Antimicrobial activity of heterotrophic bacterial communities from the marine sponge Erylus discophorus (Astrophorida, Geodiidae). PLoS One 8: e78992.

17. Biemer JJ (1973) Antimicrobial susceptibility testing by the Kirby-Bauer disc diffusion method. Ann Clin Lab Sci 3: 135-140.

18. Buckingham J (2013) Dictionary of natural products on CD-ROM, Chapman \& Hall, London.
19. Altschul SF, Madden TL, Schäfeer AA, Zhang J, Zhang Z, et al. (1997) Gapped BLAST and PSI-BLAST: A new generation of protein database search programs. Nucleic Acids Res 25: 3389-3402.

20. Labeda DP, Goodfellow M, Brown R, Ward AC, Lanoot B, et al. (2012) Phylogenetic study of the species within the family Streptomycetaceae. Antonie Van Leeuwenhoek 101: 73-104.

21. Zhang $H$, Zhang $W$, Jin $Y$, Jin M, Yu X (2008) A comparative study on the phylogenetic diversity of culturable actinobacteria isolated from five marine sponge species. Antonie Van Leeuwenhoek 93: 241-248.

22. Hedi A, Sadfi N, Fardeau ML, Rebib H, Cayol JL, et al. (2009) Studies on the biodiversity of halophilic microorganisms isolated from El-Djerid salt lake (Tunisia) under aerobic conditions. Int J Microbiol 2009: 731-786.

23. Reghioua S, Boughachiche F, Zerizer H, Oulmi L, Kitouni M, et al. (2006) Activité antibactérienne d'actinomycètes rares isolés d'échantillons de sol aride du Sud-est Algérien. Antibiotiques 8: 147-152.

24. Zang J, Wolfe S, Demain AL (1987) Effect of ammonium as nitrogen source of Delta-(L-amino adipyl)-L-cysteinyl-D-valine synthetase by Cephalosporium acremonium. J Antibiot 40: 1746-1750.

25. Voelker F, Altaba S (2001) Nitrogen source governs the patterns of growth and pristinamycin production in Streptomyces pristinaespiralis. Microbiology 147 2447-2459.

26. Kuster E, Neumier W (1981) Halotolerance in some streptomycetes producing tetracyclines. Zbl Bact Suppl 11: 315-319.

27. Omura $S$ (1992) The search for bioactive compounds for microorganisms. New York: Springer-Verlag 281-298.

28. Aouiche A, Sabaou N, Meklat A, Zitouni A, Mathieu F, et al. (2012) Antimicrobial activity of a Saharan Streptomyces spp. PAL111 strain against various clinical and toxinogenic microorganisms resistant to antibiotics. J Mycol Med 22: 42-51

29. Manteca A, Jung HR, Schwämmle V, Jensen ON, Sanchez J (2010) Quantitative proteome analysis of Streptomyces coelicolor non-sporulating liquid cultures demonstrates a complex differentiation process comparable to that occurring in sporulating solid cultures. J Proteome Res 9: 4801-4811.

30. Manteca A, Sanchez J (2010) Streptomyces developmental cycle and secondary metabolite production. Current Research, Technology and Education Topics in Applied Microbiology and Microbial Biotechnology 1: 560-566.

31. Roh C, Seo SH, Choi KY, Cha M, Pandey BP, et al. (2009) Regioselective hydroxylation of isoflavones by Streptomyces avermitilis MA-4680. J Biosci Bioeng 108: 41-46.

32. Wellington EM, Boxall AB, Cross P, Feil EJ, Gaze WH, et al. (2013) The role of the natural environment in the emergence of antibiotic resistance in gramnegative bacteria. Lancet Infect Dis 13: 155-165. 